\title{
Worldwide Diaspora of Aethina tumida (Coleoptera: Nitidulidae), a Nest Parasite of Honey Bees
}

\author{
ZACHARY LOUNSBERRY, ${ }^{1}$ SEBASTIAN SPIEWOK, ${ }^{2}$ STEPHEN F. PERNAL, ${ }^{3}$ TAD S. SONSTEGARD, ${ }^{4}$ \\ W. MICHAEL HOOD,${ }^{5}$ JEFFERY PETTIS, ${ }^{1}$ PETER NEUMANN,${ }^{6,7,8}$ AND JAY D. EVANS ${ }^{1,9}$
}

\begin{abstract}
Ann. Entomol. Soc. Am. 103(4): 671-677 (2010); DOI: 10.1603/AN10027
ABSTRACT Native to sub-Saharan Africa, Aethina tumida Murray (Coleoptera: Nitidulidae) is now an invasive pest of honey bee, Apis mellifera L., colonies in Australia and North America. Knowledge about the introduction(s) of this beetle from Africa into and among the current ranges will elucidate pest populations and invasion pathways and contribute to knowledge of how a parasite expands in new populations. We examined genetic variation in adult beetle samples from the United States, Australia, Canada, and Africa by sequencing a 912-base pair region of the mitochondrial DNA cytochrome $c$ oxidase subunit I gene and screening 10 informative microsatellite loci. One Canadian introduction of small hive beetles can be traced to Australia, whereas the second introduction seems to have come from the United States. Beetles now resident in Australia were of a different African origin than were beetles in North America. North American beetles did not show covariance between two mitochondrial haplotypes and their microsatellite frequencies, suggesting that these beetles have a shared source despite having initial genetic structure within their introduced range. Excellent dispersal of beetles, aided in some cases by migratory beekeeping and the bee trade, seems to lead to panmixis in the introduced populations as well as in Africa.
\end{abstract}

KEY WORDS invasive species, DNA barcode, Aethina tumida, Apis mellifera, pollination

Ecological and economic impacts brought on by the anthropogenic introductions of plants or animals are often more severe when introduced species have outpaced their parasites (Folgarait et al. 2002). In some cases, parasites and pathogens rejoin their original hosts or relatives in completely novel environments for both partners (e.g., the worldwide spread of the fungus responsible for Asian soybean rust; Pivonia and Yang 2004). A genetic understanding of how parasites rejoin their hosts, and how these species interact in novel environments, can address fundamental questions related to founder effects, inbreeding, and the effects of host or parasite genetic diversity on parasite success. This understanding also can help mitigate the economic or ecological impacts of parasites on both

${ }^{1}$ USDA-ARS Bee Research Laboratory, BARC-East Bldg. 476, Beltsville, MD 20705

${ }_{2}^{2}$ Deutscher Bauernverlag GmbH, Wilhelmsaue 37, 10713 Berlin, Germany.

${ }^{3}$ Agriculture and Agri-Food Canada, P.O. Box 29, Beaverlodge, AB TOH $0 \mathrm{C} 0$, Canada.

${ }^{4}$ USDA-ARS Bovine Functional Genomics Laboratory, BARC-East Bldg. 200, Beltsville, MD 20705.

${ }^{5}$ Department of Entomology, Clemson University, Clemson, SC 29634-0315

${ }^{6}$ Swiss Bee Research Centre, Agroscope Liebefeld-Posieux Research Station ALP, CH-3033 Bern, Switzerland.

${ }^{7}$ Department of Zoology and Entomology, Rhodes University, Grahamstown 6140, South Africa.

${ }^{8}$ Eastern Bee Research Institute of Yunnan Agricultural University, Heilongtan, Kunming, Yunnan Province, China.

${ }^{9}$ Corresponding author, e-mail: jay.evans@ars.usda.gov. their original hosts and on novel hosts to which they might be introduced (Krkošek et al. 2005).

Aethina tumida Murray (Coleoptera: Nitidulidae) is a parasite of honey bee, Apis mellifera L., colonies (Lundie 1940, Neumann and Elzen 2004). Larval and adult A. tumida feed on honey, pollen, bee larvae, as well as dead adult bees (Lundie 1940, Ellis et al. 2002, Spiewok and Neumann 2006). Feeding larvae can cause especially severe damage to combs of both African and European honey bees (Lundie 1940, Schmolke 1974), in some cases resulting in the full structural collapse of the nest (Hepburn and Radloff 1998). Although A tumida have only minor impacts on managed and wild honey bee colonies in their African native range (Neumann and Elzen 2004), these beetles have had severe impacts on domesticated honey bee colonies after two recent range expansions to North America and Australia (Neumann and Elzen 2004, Spiewok et al. 2007). Furthermore, they have shown an ability to exploit colonies of the distantly related social bumble bee Bombus impatiens Cresson in North America (Spiewok and Neumann 2006, Hoffmann et al. 2008) and stingless bees in Africa (Mutsaers 2006) and Australia (Greco et al. 2010).

Beekeepers and inspectors first noticed A. tumida in the United States in 1996 in South Carolina (Neumann and Elzen 2004). Honey bees in the United States are inspected fairly closely both by beekeepers and by local agricultural inspectors, and it is assumed that the arrival of this distinctive parasite into the southeastern 
United States was recognized not long after its introduction. By 1999, A. tumida had been described from numerous sites across three states (Florida, Georgia, and South Carolina) and in the adjoining state North Carolina (Hood 2000). This beetle has since spread rapidly throughout the United States (Neumann and Ellis 2008), although populations continue to be highest in the southern states (Spiewok et al. 2007).

Small hive beetles were first noticed in southeastern Australia in 2001 (Neumann and Elzen 2004), and their populations there had reached high local densities by 2005 (Spiewok et al. 2007). They have now expanded their range to much of the coastal east of Australia up to Cairns (Neumann and Ellis 2008). Furthermore, in 2007 A. tumida was first reported from Western Australia in the Ord River Irrigation Area near the town of Kununurra. Their current distribution in Western Australia seems to be restricted to this area (S.F.P., unpublished data).

Three discrete introductions have occurred in Canada. In 2002, A. tumida were first transferred into the country in a truckload of beeswax cappings shipped from Texas to a rendering facility in the province of Manitoba, Canada, where they were later eradicated (Dixon and Lafrenière 2003). The second introduction, also eradicated, was detected in 2006 as a small number of nonreproducing adults in honey bee colonies from Alberta (Canada) and Manitoba (Lafrenière 2007, Nasr 2007). A third population of A. tumida was identified in 2008 from the province of Quebec, Canada, in areas near the Canada-U.S. border (Evans 2010).

As the diaspora of A. tumida unfolds, it is still possible to predict source populations, bottlenecks during their movement, and changing genetic structure in their expanding population. Establishing the origins of A. tumida populations can answer applied questions involving regulation and mitigation and provide a rare map of a parasite racing to catch up with a worldwide species after both have reached new continents via human commerce.

Here, we investigate mitochondrial DNA ( $\mathrm{mtDNA}$ ) haplotypes (Evans et al. 2000, 2003) and microsatellite frequencies (Evans et al. 2008) for these samples, contrasting genetic signatures within the various incipient populations and between these populations and beetles collected across their native range in southern Africa. We provide evidence for minimal genetic structure across introduced populations in the United States, separate African introductions of $A$. tumida into the United States and Australia, and an Australian source of beetles intercepted in Alberta and Manitoba. In contrast, genotypes of beetles genotyped in Quebec indicate a migration directly from the United States. The presented mitochondrial and microsatellite data can serve as a baseline for tracking future movement by this serious honey bee pest.

\section{Materials and Methods}

Adult A. tumida were collected directly from a total of 146 honey bee hives from 49 sites and were then
Table 1. Collection sites by country for mitochondrial DNA screening

\begin{tabular}{llr}
\hline \hline \multicolumn{1}{c}{ Country } & \multicolumn{1}{c}{ Site name } & Sample size \\
\hline Australia & Benten Rafer & 6 \\
Australia & Bathurst (NSW) & 6 \\
Australia & Freeman & 6 \\
Australia & Highvale & 11 \\
Australia & Richmond (NSW) & 5 \\
Burkina Faso & Burkina Faso & 2 \\
Cameroon & Botanical Garden & 1 \\
Canada & High Prairie, Alb. & 1 \\
Canada & Vegaville, Alb. & 1 \\
Canada & Quebec & 2 \\
Canada & Ashville Man. & 1 \\
South Africa & Cape Point & 1 \\
South Africa & Georgetown & 2 \\
South Africa & Ixopo & 2 \\
South Africa & Nvstel & 1 \\
South Africa & Port Elizabeth & 1 \\
South Africa & Potch & 1 \\
South Africa & Richmond & 1 \\
United States & Various ${ }^{a}, 28$ sites & 410 \\
Zimbabwe & Zimbabwe & 5 \\
\hline
\end{tabular}

${ }^{a}$ Described in Evans et al. (2003).

preserved in either $90 \%$ ethanol or propanediol before genetic analyses. To cover the southern and the northern limit of the natural distribution range of A. tumida in sub-Saharan Africa (Neumann and Ellis 2008), samples were included from South Africa $(n=14)$, Zimbabwe $(n=12)$, Burkina Faso $(n=3)$, and Cameroon $(n=1)$. To investigate potential changes in genetic structure in the introduced U.S. population, samples from the first U.S. interceptions (1997-1999) were augmented by samples collected in 2000-2004 across the expanding range of $A$. tumida in southeastern North America (total $n=410$ beetles from 29 counties in Georgia, North Carolina, Florida, and South Carolina). Additional samples were gathered from a newly established population in Australia in 2005-2006 (summarized in Table 1 and Supplemental Table 1; Fig. 1) and from Canadian introductions into Alberta (Clay 2006, Nasr 2007) and Manitoba in 2006 (Lafrenière 2007) and Quebec in 2008 (Evans 2010). After collection, all adult beetles were identified to species using published morphological descriptions (Connell 1956, Gillogly 1965) and by comparison to specimens in the USDA-ARS Bee Research Laboratory reference collection (Beltsville, MD). Physical voucher specimens of the samples used, along with DNA vouchers, are held at the USDA-ARS Bee Research Laboratory.

Small hive beetle DNA samples were extracted in one of two ways. In most cases, individual A. tumida legs were dried overnight at room temperature in 1.5-ml microcentrifuge tubes and ground to a powder by using disposable polypropylene pestles. Two hundred microliters of $5 \%$ Chelex-100 suspension (BioRad Laboratories, Hercules, CA) were added to each sample, and samples were then vortexed for $1 \mathrm{~min}$ and placed in a $55^{\circ} \mathrm{C}$ water bath for $30 \mathrm{~min}$. The extracted DNA was diluted 1:10 before polymerase chain reaction (PCR) amplification. Alternatively, beetle abdomens from Africa were digested using pronase in $\mathrm{NaCl} /$ sucrose extraction buffer, followed by purifica- 


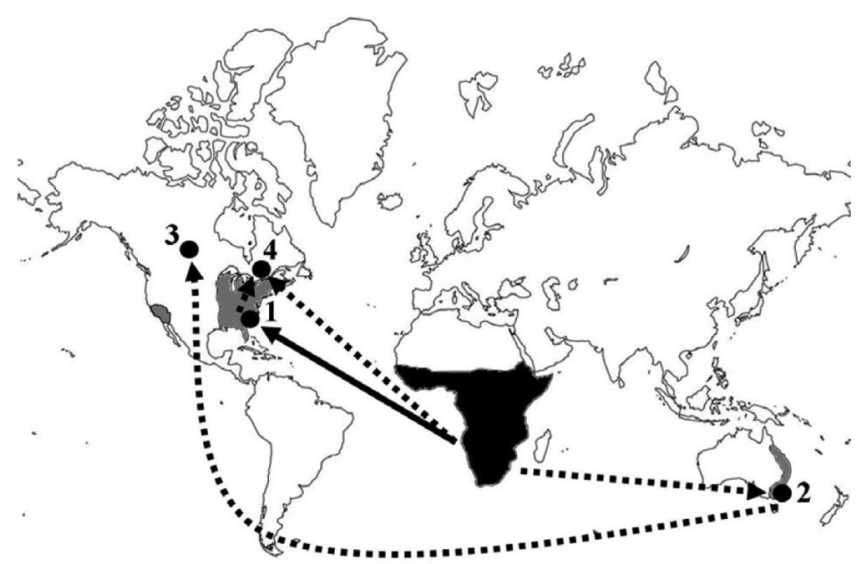

Fig. 1. Map of global small hive beetle distribution (modified from Neumann and Ellis 2008) with kind permission of the International Bee Research Association) and the global diaspora. The black area represents the native distribution range of A. tumida in sub-Saharan Africa. The gray shading indicates well-established populations in the United States and Australia (Neumann and Ellis 2008). The numbered circles represent distinct dispersal events: 1) 1996, South Carolina, United States; 2) 2001, Sydney, Australia; 3) 2006, Alberta, Canada; 4) 2008, Quebec, Canada. The solid line from Africa to the United States is a known introduction because before 1996 A. tumida had never been reported from outside of its native range. Dotted lines represent possible dispersal events indicated by our genetic data.

tion using KAc and alcohol precipitation (Evans et al. 2000).

DNA from the mitochondrial cytochrome $c$ oxidase subunit I (COI) gene was amplified using PCR primers presented by Evans et al. (2000). Two oligonucleotide primers, AT1904S (5'-GGTGGATCTTCAGTTGATTTAGC-3') and AT2953A ( $5^{\prime}$-TCAGCTGGGGGATAAAATTG-3'), effectively amplified a single band of the predicted size from A. tumida DNA. PCR conditions consisted of $93^{\circ} \mathrm{C}$ for $1 \mathrm{~min}, 54^{\circ} \mathrm{C}$ for $1 \mathrm{~min}$ and $72^{\circ} \mathrm{C}$ for $2 \mathrm{~min}$ for 35 cycles, followed by a 5 -min elongation step at $72^{\circ} \mathrm{C}$. The resulting PCR product was sequenced in one direction by BigDye Primer Sequencing reactions (University of Maryland Center for Agricultural Biotechnology, College Park, MD).

DNA sequences were edited and aligned using the software program BioEdit (Hall 1999). Sequences were then exported to the software program PAUP 4.0b10 (Swofford 2002) for phylogenetic analyses. Previous analyses found that all United States samples fall into one of two haplotypes (Evans et al. 2003). COI sequence data from a single beetle from Cameroon that had been identified based on morphology as $A$. tumida was used to root the tree. A maximum parsimony tree was constructed to show haplotype differences within and across populations.

Ten informative microsatellite loci were genotyped using primers presented by Evans et al. (2008) for loci SHB12, SHBB14, SHB19, SHB19b, SHB20, SHB25, SHBB26, SHBB35, SHBB83, and SHBB89. PCR followed a thermal protocol consisting of $96^{\circ} \mathrm{C}$ for $2 \mathrm{~min}$ and then three cycles of $96^{\circ} \mathrm{C}$ for $30 \mathrm{~s}, 60^{\circ} \mathrm{C}$ for $30 \mathrm{~s}$ $\left(-1^{\circ} \mathrm{C} /\right.$ cycle $), 65^{\circ} \mathrm{C}$ for 1 min, followed by 35 cycles of $96^{\circ} \mathrm{C}$ for $30 \mathrm{~s}, 56^{\circ} \mathrm{C}$ for $30 \mathrm{~s}, 65^{\circ} \mathrm{C}$ for $1 \mathrm{~min}$, and a final extension at $65^{\circ} \mathrm{C}$ for $2 \mathrm{~min}$. PCR product were diluted $1: 20$, and $1 \mu \mathrm{l}$ of this dilution was added to $10 \mu \mathrm{l}$ of formamide containing the LIZ size standard (Applied
Biosystems, Foster City, CA). Products were analyzed by capillary electrophoresis using an 3730XL instrument (Applied Biosystems), and marker genotypes were scored using GeneMapper version 3.7 (Applied Biosystems).

Tests for differences in mitochondrial haplotype distribution in U.S. samples were carried out across sites and years using chi square analyses and Fisher exact test (JMP7, SAS Institute, Cary, NC). Microsatellite allelic diversity was calculated using GenAlex version 6.2 (Peakall and Smouse 2006). Genetic structure based on microsatellite data was estimated using pairwise estimates for $\mathrm{F}$-statistics in a multilocus model (Weir and Cockerham 1984) and using a global Analysis of Molecular Variance (Weir and Cockerham 1984, Excoffier et al. 2005). Differences between Australian, African, and American samples were visualized using Structure 2.1 (Falush et al. 2007). Covariance between mitochondrial and microsatellite genotypes was estimated by using mtDNA haplotype to denote "population" in analyses within specific states and years.

In light of high adult mobility (Spiewok et al. 2008), it can be inferred that the lowest level of distinction between populations of adult A. tumida is the site (apiary) level. Larval A. tumida disperse many meters from their host colony before pupation and, upon reaching adulthood, are not known to exhibit fidelity to their birth colony (Neumann and Elzen 2004).

\section{Results}

Cytochrome oxidase one sequences were highly similar across all of the A. tumida samples. Excluding the outgroup from Cameroon, which differed from the next closest isolate by $4.6 \%$ (42/912 bp) the most divergent samples (e.g., AfricSAJ2 versus AfricSAD2) 


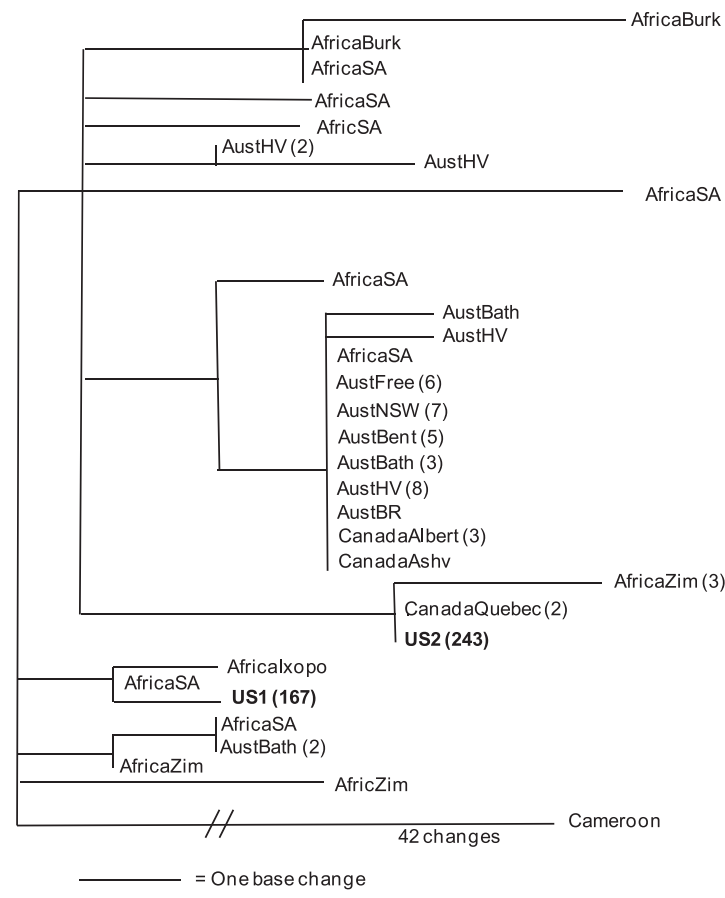

Fig. 2. Maximum-parsimony tree showing relationships among samples from Africa (Afric), the United States (NthAm), Australia (Aust), and Canada (Can). Samples with an identical haplotype are grouped on the same vertical line, whereas samples from the same geographic region are collapsed to one data point followed, in parentheses, with the number of mites represented.

differed by only $10 \mathrm{bp}(1.1 \%)$ across the 912 -bp aligned region (Fig. 2). The average sequence divergence between A. tumida samples was $0.54 \%$, excluding Cameroon. Most Australian beetles fell into a single haplotype identical to a haplotype seen in samples from Potchestroom, South Africa (Evans et al. 2000). Beetles from Alberta and Manitoba were $100 \%$ identical to this predominant Australian haplotype (Fig. 2) and differed by four and five steps from each of the two U.S. haplotypes. All new mitochondrial sequences $(n=38)$ have been deposited in GenBank under accessions HM056042-HM056079.

In the United States, beetles from the first $2 \mathrm{yr}$ of collection in two sites from South Carolina $(n=6$ beetles) were entirely of haplotype US1, an unlikely event given later frequencies of haplotype US1 in that state $(59 \%, 100 / 170 ; P<0.05)$ and in the United States as a whole $\left(40 \%, 151 / 381 ; \chi^{2}=10.9, P<0.001\right)$. The frequency of alternate haplotype US2 increased slightly in South Carolina over time, from $48 \%$ in 1998 to $57 \%$ in $2002\left(\chi^{2}=9.5, \mathrm{df}=3, P<0.05\right)$. A. tumida collected in Georgia showed an opposite trend in haplotype frequencies, from $91 \%$ US2 in 1998 to $30 \%$ US2 in 2000, $n=34$ and 17 beetles each year, respectively $\left(\chi^{2}\right.$ prob. $\left.<0.0001\right)$. Mitochondrial haplotype structure was evident within states, with significant variation in haplotype frequencies across 18 counties surveyed during 2002 in South Carolina $\left(\chi^{2}=35.5\right.$, $\mathrm{df}=17, P<0.01)$.

Allelic diversity was not significantly different across all three continents $\left(\overline{\mathrm{A}}_{\mathrm{p}-\mathrm{Africa}}=2.0, \mathrm{SE}=0.23\right.$, $\left.\overline{\mathrm{A}}_{\mathrm{p} \text {-Australia }}=2.2, \mathrm{SE}=0.20, \overline{\mathrm{A}}_{\mathrm{p} \text {-U.S. }}=2.5, \mathrm{SE}=0.26\right)$. More private alleles were seen in U.S. samples than in samples from Australia or Africa (Appendix 1., avg. 6.2 versus 0.1 versus none in the African samples), and an average of 10.8 alleles per locus $(\mathrm{SE}=1.6)$ was found in U.S. sampling versus $4.5(\mathrm{SE}=0.82)$ and $2.8(\mathrm{SE}=$ $0.25)$, respectively. These results were biased by the unequal sampling involved but nevertheless show robust diversity in both invasive populations. Mean $\mathrm{F}_{\mathrm{st}}$ between Africa and the United States was 0.157, between Australia and the United States was 0.121, and between Africa and Australia was 0.118. Across all three populations, $89 \%$ of the total genetic variance was found within populations, whereas $11 \%$ was found between populations by analysis of molecular variance, indicating significant genetic structure at the level of these three regions $(P<0.0001)$.

Comparing across states within the United States, $\overline{\mathrm{A}}_{\mathrm{p}}$ ranged from 1.83 (Georgia) to 2.30 (South Carolina), with no significant differences between states. Pairwise $\mathrm{F}_{\text {st }}$ estimates between states were low, ranging from 0.012 between Florida and South Carolina to 0.143 between Georgia and North Carolina (Fig. 2). Sample sizes were too small to carry out F-statistics at the level of smaller subpopulations (e.g., counties within states). There were no significant differences in genetic diversity across sampling years $\left(\overline{\mathrm{A}}_{\mathrm{p}}=1.7-2.42\right.$ for 1998-2002) and slight but nonsignificant signs of genetic structure across years $\left(\mathrm{F}_{\mathrm{st}}=0.126\right)$.

Despite the geographic and early temporal signals in mitochondrial haplotype frequencies, there was not a significant relationship between mitochondrial haplotype and genetic structure as estimated by the microsatellites (Fig. 3). Using samples collected across all years ( 357 beetles), $\mathrm{F}_{\mathrm{st}}$ between the two mitochondrial haplotypes was 0.007 , and this value remained low when samples collected only from 1997 to 2000 were included (0.009; 232 sampled beetles). Both U.S. haplotypes had similar allele counts and allelic diversities $\left(\overrightarrow{\mathrm{A}}_{\mathrm{p}}=2.31\right.$ and 2.19 for haplotypes US1 and US2, respectively, SEs $=0.23$ and 0.19 ).

\section{Discussion}

Small hive beetles impact honey bee colonies on three continents (Neumann and Ellis 2008) and strongly impact international trade of bees and bee products. An understanding of how this beetle disperses across and within continents can help in the development of mitigation strategies, including the restriction of both legal and undercover movement of honey bees and hive products. Here, we provide genetic evidence identifying likely source populations for introduced populations of A. tumida in Canada and Australia, and we give a picture of the great dispersal abilities of this species by itself and by humans. 

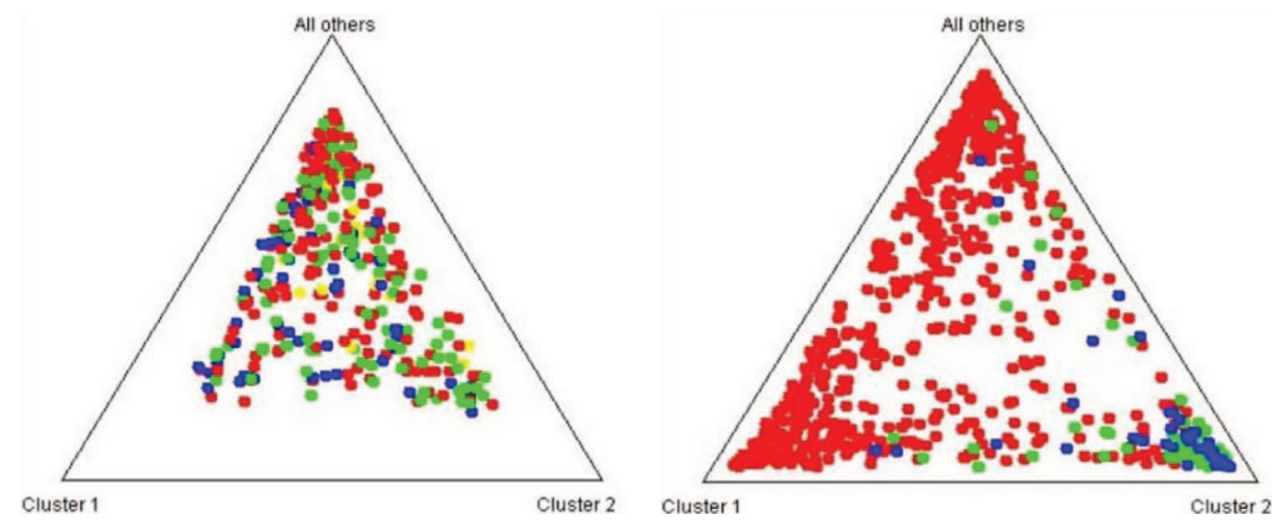

Fig. 3. Triangle plot showing microsatellite structure among four U.S. subpopulations (left) shows no significant structure present among the four U.S. states sampled across all years (red, Florida; green, North Carolina; blue, South Carolina; pink, Georgia). Contrast with the triangle plot for showing structure of African (green), Australian (blue), and U.S. (red) populations. (Online figure in color.)

Samples identified recently in Alberta and Manitoba are more similar to haplotypes from Australian samples than to those sequenced to date in the United States. This could imply one of two things: either the Australian beetles came from the same African source population as their counterparts in Alberta and Manitoba or that these province's A. tumida may have come from Australia. Because Canada has imported Australian "package bees" (cages containing a queen and $1 \mathrm{~kg}$ of worker bees) into these regions since 1988 and has never knowingly had bees introduced from Africa, this strongly favors the hypothesis that the sampled population was of Australian origin. Further supporting this hypothesis is the fact that all A. tumida specimens collected were derived specifically from beekeeping operations having recently imported package bees from that country. This supports the view that $A$. tumida long-range dispersal is fostered by apicultural trade (Neumann and Elzen 2004, Spiewok et al. 2008), which for Canada has had the negative consequence of restricting importation from countries where $A$. tumida has become endemic.

In contrast, samples collected in Quebec are closely allied to samples from the U.S. populations based on mtDNA sequence. This fact, and the relative proximity of these collections from the U.S. border $(<25 \mathrm{~km}$; Evans 2010) allows for the natural dispersal of beetles over the border (Spiewok et al. 2008), probably followed by human-aided dispersal in Canada. Both the Alberta and Quebec samples were too sparse for meaningful within-country analyses of structure using microsatellite loci.

Based on mitochondrial haplotypes, it is unclear whether A. tumida collected in the United States were derived from one or multiple source populations in Africa (Evans et al. 2000). By 1998, both haplotypes were found at roughly equal frequencies, with some state-level differences in frequency (most notably a higher frequency of US2 in Georgia and the opposite trend in South Carolina; Evans et al. 2000). This pattern also might be explained by local movement patterns and restricted female movement. The near-total lack of genetic structure across the United States shown for microsatellite genotypes, and the absence of covariance between mitochondrial haplotypes and microsatellite genotypes favor a single introduction of A. tumida into the United States. Based on this evidence, and early collections, the most parsimonious model is that A. tumida arrived in North America through a single colonization event, arguably in Georgia or South Carolina in the mid-1990s. From there, the incipient population probably benefited from high rates of human transport of bees from the southeastern United States across much of the country (Neumann and Elzen 2004, Neumann and Ellis 2008). Although the recency of movement precludes quantitative estimates of migration rates, the minimal structure shown via microsatellite genotypes indicates continued high levels of gene flow across populations within the United States, consistent with known human transport of bees over thousands of kilometers and longdistance flight by adult A. tumida (Spiewok et al. 2008).

Mitochondrial DNA patterns across southern Africa indicate similarly widespread movement of maternal lineages within the native range. Because migratory beekeeping is far less frequent compared with the United States (at least north of South Africa; Johannsmeier 2001) and traditional bark hive beekeeping is common in many countries (Hepburn and Radloff 1998), this suggests that actively flying A. tumida (Spiewok et al. 2008) and/or migratory host colonies (Hepburn and Radloff 1998) contribute to gene flow.

Although there are no data suggesting that the $A$. tumida is a severe pest in its native range (Hepburn and Radloff 1998, Johannsmeier 2001) or in Canada, honey bee populations in the United States and Australia are suffering because of their introduction (Neumann and Elzen 2004, Spiewok et al. 2007). Since their introduction into the United States, efforts have been made to limit A tumida populations via mechanical, chemical, and biological methods (Ellis et al. 2003, Hood and Miller 2005, Buchholz et al. 2006, Neumann and Hoffmann 2008). The ongoing success of this 
invasive species despite these control efforts indicates that dispersal will continue with subsequent risks for both honey bees and alternate native bee hosts such as bumble bees and stingless bees. An improved understanding of the routes of A. tumida migration can help in regulation strategies and, arguably, in determining the effective host and climate range of this spreading parasite. Moreover, A. tumida are predicted to suffer from bottlenecks associated with those faced by their honey bee hosts. Although this study indicates that A. tumida movement has not drastically reduced genetic diversity in incipient populations of this species, further anthropogenic movement across commercial honey bee populations might have a more severe impact on standing diversity and genetic traits.

\section{Acknowledgments}

We thank Marco Porporato for samples from Burkina Faso and Dawn Lopez for laboratory assistance. Access to Canadian samples was facilitated by Maria Perrone and André Vallières of the Canadian Food Inspection Agency, and samples were supplied by S.F.P., Medhat Nasr, Alberta Agriculture and Rural Development, as well as Claude Boucher and Isabelle Côté of the Ministère de l'Agriculture, des Pêcheries et de l'Alimentation du Québec.

\section{References Cited}

Buchholz, S., P. Neumann, K. Merkel, and H. R. Hepburn. 2006. Evaluation of Bacillus thuringiensis Berliner as an alternative control of small hive beetles, Aethina tumida Murray (Coleoptera: Nitidulidae). J. Pest Sci. 79: 251-254.

Clay, H. 2006. Small hive beetle in Canada. Hivelights 19: $14-16$.

Connell, W. 1956. Nitidulidae of Delaware. Delaware Agric. Exp. Stat Bull. 318: 1-67.

Dixon, D., and R. Lafrenière. 2003. Manitoba provincial report, pp. 17-18. Proceedings of the Canadian Association of Professional Apiculturists, 4 Dec 2002, Niagara Falls, ON, Canada.

Ellis, J. D., Jr., P. Neumann, R. Hepburn, and P. J. Elzen. 2002. Longevity and reproductive success of Aethina tumida (Coleoptera: Nitidulidae) fed different natural diets. J. Econ. Entomol. 95: 902-907.

Ellis, J. D., Jr., K. S. Delaplane, R. Hepburn, and P. J. Elzen. 2003. Efficacy of modified hive entrances and a bottom screen device for controlling Aethina tumida (Coleoptera: Nitidulidae) infestations in Apis mellifera ( $\mathrm{Hy}$ menoptera: Apidae) Colonies. J. Econ. Entomol. 96: 16471652.

Evans, B. 2010. Small hive beetle infestation (Aethina tumida), Canada (follow-up report no. 2). OIE. World Animal Health Information Database, vol. 23, no. 5. (http://www.oie.int/ wahis/public.php?page $=$ weekly_report_index\&admin $=0)$.

Evans, J. D., J. S. Pettis, and H. Shimanuki. 2000. Mitochondrial DNA relationships in an emergent pest of honey bees: Aethina tumida (Coleoptera: Nitidulidae) from the United States and Africa. Ann. Entomol. Soc. Am. 93: $415-420$.

Evans, J. D., J. S. Pettis, W. M. Hood, and H. Shimanuki. 2003. Tracking an invasive honey bee pest: mitochondrial DNA variation in North American small hive beetles. Apidologie 34: 103-109.

Evans, J. D., S. Spiewok, E. W. Teixeira, and P. Neumann. 2008. Microsatellite loci for the small hive beetle, Aethina tumida, a nest parasite of honey bees. Mol. Ecol. Resour. 8: $698-700$.

Excoffier, L., G. Laval, and S. Schneider. 2005. Arlequin version 3.0: an integrated software package for population genetics data analysis. Evol. Bioinform. Online 1: 47-50.

Falush, D., M. Stephens, and J. K. Pritchard. 2007. Inference of population structure using multilocus genotype data: dominant markers and null alleles. Mol. Ecol. Notes 7: 574-578.

Folgarait, P. J., O. A. Bruzzone, R. J. Patrock, and L. E. Gilbert. 2002. Developmental rates and host specificity for Pseudacteon parasitoids (Diptera: Phoridae) of fire ants (Hymenoptera: Formicidae) in Argentina. J. Econ. Entomol. 95: 1151-1158.

Gillogly, L. R. 1965. A key to the genera of the subfamily Nitidulinae (Nitidulidae, Coleoptera) and description of a new genus and a new species. Occasional Papers of the Bureau of Entomology California Department of Agriculture 8: 1-24.

Greco, M. K., D. Hoffmann, A. Dollin, M. Duncan, R. Spooner-Hart, and P. Neumann. 2010. The alternative Pharaoh approach: stingless bees mummify beetle parasites alive. Naturwissenschaften. 97: 319-323.

Hall, T. 1999. BioEdit: a user-friendly biological sequence alignment and analysis program for Windows 95/98/NT. Nucleic Acids Symp. Ser. 41: 95-98.

Hepburn, H. R., and S. E. Radloff. 1998. Honeybees of Africa. Springer, New York.

Hoffmann, D., J. S. Pettis, and P. Neumann. 2008. Potential host shift of the small hive beetle (Aethina tumida) to bumblebee colonies (Bombus impatiens). Insectes Soc. 55: 153-162.

Hood, W. M. 2000. Overview of the small hive beetle, Aethina tumida, in North America. Bee World 81: 129_ 137.

Hood, W. M., and G. A. Miller. 2005. Evaluation of an upper hive entrance for control of Aethina tumida (Coleoptera: Nitidulidae) in colonies of honey bees (Hymenoptera: Apidae). J. Econ. Entomol. 98: 1791-1795.

Johannsmeier, M. F. (ed.). 2001. Beekeeping in South Africa, 3rd ed. Reviews Plant Protection Research Institute Handbook No. 14

Krkošek, M., M. A. Lewis, and J. P. Volpe. 2005. Transmission dynamics of parasitic sea lice from farm to wild salmon. Proc. R. Soc. Lond. Ser. B Biol. Sci. 272: 689-696.

Lafrenière, R. 2007. Manitoba provincial report, pp. 31-33. Proceedings of the Canadian Association of Professional Apiculturists, 24-25 Jan 2007, Langley, BC, Canada.

Lundie, A. 1940. The small hive beetle Aethina tumida. Science Bulletin 220. South African Department of Agriculture and Forestry, Pretoria, South Africa.

Mutsaers, M. 2006. Beekeepers' observations on the small hive beetle (Aethina tumida) and other pests in bee colonies in West and East Africa. In Proceedings of the 2nd EurBee Conference, Prague, Czech Republic.

Nasr, M. 2007. Alberta provincial report, pp. 28-30. Proceedings of the Canadian Association of Professional Apiculturists, 24-25 Jan 2007, Langley, BC, Canada.

Neumann, P., and P. J. Elzen. 2004. The biology of the small hive beetle (Aethina tumida, Coleoptera: Nitidulidae) gaps in our knowledge of an invasive species. Apidologie 35: 229-247.

Neumann, P., and J. D. Ellis. 2008. The small hive beetle (Aethina tumida Murray, Coleoptera: Nitidulidae): distribution, biology and control of an invasive species. J. Apic. Res. 47: 181-183.

Neumann, P., and D. Hoffmann. 2008. Small hive beetle diagnosis and control in naturally infested honeybee col- 
onies using bottom board traps and CheckMite + strips. J. Pest. Sci. 81: 43-48.

Peakall, R., and P. Smouse. 2006. GENALEX 6: genetic analysis in Excel. Population genetic software for teaching and research. Mol. Ecol. Notes 6: 288-295.

Pivonia, S., and X.-B. Yang. 2004. Assessment of the potential year-round establishment of soybean rust throughout the world. Plant Dis. 88 523-529.

Schmolke, M. D. 1974. A study of Aethina tumida: the small hive beetle. University of Rhodesia Certificate in Field Ecology Project Report, Salisbury (Harare).

Spiewok, S., M. Duncan, R. Spooner-Hart, J. S. Pettis, and P. Neumann. 2008. Small hive beetle, Aethina tumida, populations II: dispersal of small hive beetles. Apidologie 39: 683-693.

Spiewok, S., and P. Neumann. 2006. Infestation of commercial bumblebee (Bombus impatiens) field colonies by small hive beetles (Aethina tumida). Ecol. Entomol. 31: $623-628$.

Spiewok, S., J. S. Pettis, M. Duncan, R. Spooner-Hart, D. Westervelt, and P. Neumann. 2007. Small hive beetle, Aethina tumida, populations I: infestation levels of honeybee colonies, apiaries and regions. Apidologie 38: 595605.

Swofford, D. L. 2002. PAUP*: phylogenetic analysis using parsimony (*and other methods). Version 4. Sinauer, Sunderland, MA.

Weir, B. S., and C. C. Cockerham. 1984. Estimating F-statistics for the analysis of population structure. Evolution 38: $1358-1370$.

Received 16 February 2010; accepted 8 April 2010. 